\title{
Correction to: Morphology and Mechanical, Corrosive, and Antibacterial Behaviors of Indirectly Extruded Zn-0.05 wt.\%Mg-(0.5, 1 wt.\%)Ag Alloys
}

\author{
C. Xiao, D.W. Zhao, Q. Sun, Y. Su, D.P. Cui, X.Z. Zhang, X.L. Dong, H.X. Wang, F. Wang, Y.P. Ren, and G.W. Qin
}

\section{Correction to: JMEPEG https://doi.org/10.1007/s11665-019-04297-4}

The article "Morphology and Mechanical, Corrosive, and Antibacterial Behaviors of Indirectly Extruded $\mathrm{Zn}$ 0.05 wt.\%Mg-(0.5, 1 wt.\%)Ag Alloys", written by C. Xiao, D. W. Zhao, Q. Sun, Y. Su, D. P. Cui, X. Z. Zhang, X. L. Dong, H. X. Wang, F. Wang, Y. P. Ren, and G. W. Qin, was originally published electronically on the publisher's internet portal (currently SpringerLink) on 11 September 2019 with open access. With the author(s)' decision to step back from Open Choice, the copyright of the article changed in October 2019 to (C) ASM International 2019 and the article is forthwith distributed under the terms of copyright.

The original article has been corrected.

Publisher's Note Springer Nature remains neutral with regard to jurisdictional claims in published maps and institutional affiliations.

The original article can be found online at https://oi.org/10.1007/ s11665-019-04297-4.

C. Xiao, Department of Orthopedics, Affiliated Zhongshan Hospital of Dalian University, Dalian 116001, China; and Key Laboratory for Anisotropy and Texture of Materials (Ministry of Education), School of Materials Science and Engineering, Northeastern University, Shenyang 110819, China; D.W. Zhao, Q. Sun, Y. Su, D.P. Cui, X.Z. Zhang, X.L. Dong, H.X. Wang, and F. Wang, Department of Orthopedics, Affiliated Zhongshan Hospital of Dalian University, Dalian 116001, China; and Y.P. Ren and G.W. Qin, Key Laboratory for Anisotropy and Texture of Materials (Ministry of Education), School of Materials Science and Engineering, Northeastern University, Shenyang 110819, China. Contact e-mails: zhaodewei2016@163.com and qingw@smm.neu.edu.cn. 